Faruk Abdullahi Mohammed ${ }^{1,2, \#, ~ K e h i n d e ~ K a z e e m ~ K a n m o d i ~}{ }^{1,3, *, *}$, Omotayo Francis Fagbule ${ }^{3}$,

Miracle Ayomikun Adesina ${ }^{3}$, Nwafor Jacob Njideka4, Hamza Abubakar Sadiq ${ }^{5}$

\title{
Shisha Smokers' Desire To Quit Shisha Smoking Habit: Findings From A Nigerian Pilot Survey
}

\author{
'Dental Clinic, Kebbi State Medical Centre, Kalgo, Nigeria \\ 2Department of Oral and Maxillofacial Surgery, Jaipur Dental College, Maharaj Vinayak Global University, Jaipur, Rajasthan, India \\ ${ }^{3}$ Cephas Health Research Initiative Inc, Ibadan, Nigeria \\ 43D Media Inc, Abakaliki, Nigeria \\ ${ }^{5}$ Department of Community Health, Kebbi State Primary Health Care Development Agency, Birnin Kebbi, Nigeria \\ *email: kanmodikehindedayahoo.com \\ "Both authors had equal contributions \\ DOI: 10.2478/gp-2019-0004 \\ Received: 25 January 2019; Accepted: 30 January 2019
}

\begin{abstract}
Objectives: To explore the reasons why shisha smokers indulge in shisha smoking habit, and to also explore their attitudes towards quitting shisha smoking habit. Methods: A total of 45 current shisha smokers participated in the study. The study tool was a paper questionnaire. Snowballing technique was the sampling method adopted in the recruitment of study participants. Data obtained was analyzed using the SPSS version 20 software. Results: The mean $( \pm S D)$ age of the participants was $25.8( \pm 5.5)$ years and majority (71.1\%) of them were males. The top two reasons why the participants smoke shisha were: "for pleasure" (40\%); and "to feel among" (33.3\%). The majority (66.7\%) of the participants wanted to quit shisha smoking habits. However, only 54.5\% (18/33) of them indicated that they made efforts at quitting the behavior within the past one year. Also, only 66.7\% (28/42) and 65.6\% (21/32) of those participants who had a close friend and a close family member/relative that smoke shisha, respectively, wanted to quit shisha smoking habit. Conclusion: This study shows diverse reasons why shisha smokers engage in shisha smoking habit. Also, many of these smokers were willing to quit shisha smoking habits but, unfortunately, they are yet to quit the habit. This demonstrates the need for social support of shisha smokers in our environment towards quitting shisha smoking habit.
\end{abstract}

\section{Keywords}

Shisha, tobacco, smokers, hookah, waterpipe, quit, cessation, addiction, habit, Nigeria.

\section{INTRODUCTION}

Shisha smoking, also called waterpipe/hookah/hubble bubble/ narghile smoking, is a form of addictive behaviour that is gaining more and more popularity in our present day society (Maziak et al 2005, Martinasek et al 2011, Afifi et al 2013, Caroll et al 2014, World Health Organization (WHO) 2014, WHO Study Group on Tobacco Product Regulation (TobReg) 2015, British Heart Foundation 2019). According to the British Heart Foundation, shisha smoking is defined as a way of smoking tobacco, sometimes mixed with fruit or molasses sugar, through a bowl and hose or tube (British Heart Foundation 2019).

Shisha smokers, often times, do not smoke shisha alone but smoke it in the company of their loved ones (Maziak et al 2005, Martinasek et al 2011, Afifi et al 2013, Caroll et al 2014). In fact, some families engage in shisha smoking at social and family gatherings (Afifi et al 2013, WHO Study Group on Tobacco Product Regulation (TobReg) 2015).

Shisha has tobacco as one of its major constituents (Bahelah 2014, WHO Study Group on Tobacco Product Regulation (TobReg) 2015); this implies that shisha smoking has a stimulatory effect (Bahelah 2014, WHO Study Group on Tobacco Product Regulation (TobReg) 2015). Unfortunately, more and more people in the young and middle ages of life form the majority of the people smoking shisha (WHO Regional Office for Africa 2012, WHO Study Group on Tobacco Product Regulation (TobReg) 2015, Kanmodi et al 2018, British Heart Foundation 2019). In fact, the shisha smoking rate amongst these age groups had overtaken the rate of cigarette smoking in some of our present day societies (WHO Study Group on Tobacco Product Regulation (TobReg) 2015, WHO 2015, British Heart Foundation, 2019). A suggested reason why 
shisha smoking rate is overtaking that of the cigarette may be because of its stimulatory effect coupled with its higher level of social acceptance when compared to cigarette use (Maziak et al 2005, Martinasek et al 2011, Afifi et al 2013, Caroll et al, 2014).

There are many reasons why people indulge in shisha smoking habit. Studies had shown that people engage in this habit for pleasure and relaxation and also as a result of peer influence, life problems, distress and anxiety, personality, living alone and many more (Al-Naggar \& Saghir 2011, Momenabadi et al 2016, Mugyenyi et al 2018, Al-Rawi et al 2018).

Focusing on Nigeria as a country, shisha is becoming a more and more popular source of smoked tobacco amongst its citizens because more and more shisha smoking venues being erected in restaurants and discos in some major Nigerian cities (WHO Regional Office for Africa 2012,Kanmodi et al 2018). However, virtually, no study had been conducted in Nigeria to explore reasons why Nigerians engage in shisha smoking habits, unlike for some other countries where factors responsible for shisha smoking had been well explored (Al-Naggar \& Saghir 2011, Momenabadi et al 2016, Mugyenyi et al 2018, Al-Rawi et al 2018).

On the basis of the above, it becomes imperative to conduct a survey exploring shisha smoking habit amongst shisha smokers in Nigeria. Hence, this study aims to survey a sample of shisha smokers in Birnin Kebbi Local Government Area (LGA), Kebbi State, Nigeria, exploring [1] the reasons why they indulge in shisha smoking habits and [2] their attitudes towards quitting shisha smoking habit. This study is of utmost significance to the body of scientific knowledge as the study forms, to the best of the authors' knowledge, the first of its kind in the Nigerian society. Also, the findings made from this study will give a picture of the rationale behind shisha use amongst current shisha smokers in Birnin Kebbi, Nigeria.

\section{MATERIAL AND METHODS}

\section{Nature of the study}

This study was a cross-sectional pilot survey of 45 current shisha smokers in Birnin Kebbi LGA, Kebbi State, Nigeria. This study forms part of the 'Campaign for Head and Neck Cancer Education (CHANCE)' project conducted by the authors.

\section{Study Area}

Birnin Kebbi (our study area) is the capital of Kebbi State. Kebbi State is a rural state located in the northwestern part of Nigeria. On the basis of the 2006 population statistics, Birnin Kebbi has a total population of about 268,620 people, of which about $50.3 \%$ of them are people aged 15-64 years (City Population, 2019). The majority of the inhabitants of the town were the Hausa and Fulani people and practicing Islamic religion (Encyclopaedia Britannica 2019).

\section{Study Instrument}

The study instrument was a paper questionnaire that was developed from previous similar studies (Al-Naggar \& Saghir 2011, Momenabadi et al 2016, Mugyenyi et al 2018, Al-Rawi et al 2018). The questionnaire was then given to an educationist and some three dentists who were clinical and public health experts in tobacco research. The comments and suggestions given by them were used to develop the final draft of the questionnaire. The final draft of the questionnaire had three sections - a section obtaining socio-demographic information (such as age, sex, level of formal education, religion and tribe), a section exploring reasons for taking shisha and a section exploring attitudes towards shisha smoking cessation.

\section{Sampling}

A convenient sample size of 50 current shisha smokers was estimated for this pilot study, because the study is virtually the first of its kind in the Nigerian setting. Owing to the difficulty in locating current shisha smokers independently, authors adopted the use of snowballing technique to recruit the study subjects.

\section{Participants' Selection}

The eligibility criteria for participant selection were selfidentification as a current shisha smoker, with evidence of possession of a shisha; and literacy. All participants were visited either at home or at shisha smoking places. Only those who gave verbal informed consent were recruited for the study.

\section{Data Collection and Analysis}

A total of 45 current shisha smokers participated in the study. All questionnaires filled were self-administered. Data collected were cleaned, coded, computed and analysed using the SPSS version 20 Software. The frequencies of all variables were determined. Comparisons between qualitative variables were performed using the Chi square test, with the level of statistical significance set at a $p$-value of $<0.05$. The results of data analysis were presented using tables and chart. 


\section{Ethical Considerations}

This study was conducted under compliance with the Helsinki Declaration on research involving human subjects. Approval to carry out the study was obtained from the Kebbi Medical Centre, Kebbi State, Nigeria. All participants were well informed about the purpose of the study. They were informed about the purpose of the study; they were also informed that their participation was anonymous, voluntary and strictly confidential. All study participants gave verbal-informed consent before participation. Also, no participant was inflicted with any harm in the course of the study.

\section{RESULT}

The response rate for the study was $90 \%$. The mean $( \pm S D)$ age of the participants was $25.8( \pm 5.5)$ years, 32 were men, 16 had secondary school education and 27 had tertiary school education. Virtually, all (42/45) of the participants had a close friend who also smokes shisha, whilst only 32 had a family member/relative who smokes shisha (Figure 1). The top two reasons why the participants smoke shisha were 'for pleasure' (40\%) and 'to feel amongst' (33.3\%) (Table 1).

The majority (32/45) of the participants wanted to quit shisha smoking habit. Amongst those participants who wanted to quit shisha smoking habit, only 18 of them indicated that they made efforts at quitting the behaviour within the past 1 year (Table 2). Only $66.7 \%$ (28/42) and $65.6 \%$ (21/32) of those participants who had a close friend and a close family member/relative who smoke shisha, respectively, wanted to quit shisha smoking habit.

\section{DISCUSSION}

In this study, we surveyed a sample of current shisha smokers exploring the reasons why they indulge in shisha smoking habits and also their attitudes towards quitting of shisha use. Our survey data gave interesting findings. To start with, the mean age of the participants shows that the majority of the surveyed shisha users were young adults. This finding on the average age of our study participants is similar to that reported in similar studies conducted amongst foreign population groups (AlNaggar \& Sagir 2011, Joveini et al 2016, Davaji et al 2017).

The majority of the participants had a close friend/family member/relative who smokes shisha (Figure 1); this finding is consistent with what has been earlier reported amongst shisha smokers in other countries (Maziak et al 2005, WHO Study Group on Tobacco Product Regulation (TobReg) 2015,

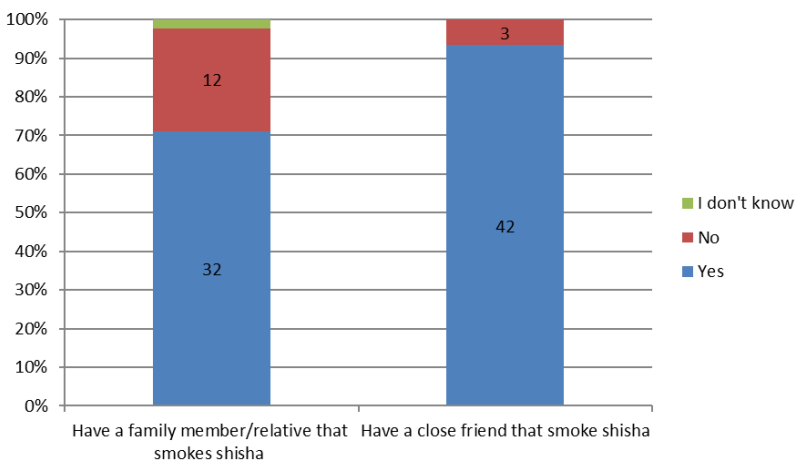

Figure 1. Frequency of participants with close friends and family members/relatives who also smoke shisha

Table 1. Reasons why participants engage in shisha smoking habits

\begin{tabular}{|l|l|l|l|}
\hline Reasons & Yes (\%) & No (\%) & No response (\%) \\
\hline To feel high & $11(24.4)$ & $33(73.3)$ & $1(2.2)$ \\
\hline To feel amongst & $15(33.3)$ & $23(51.1)$ & $7(15.6)$ \\
\hline $\begin{array}{l}\text { To forget about } \\
\text { worries }\end{array}$ & $11(24.4)$ & $33(73.3)$ & $1(2.2)$ \\
\hline $\begin{array}{l}\text { To get more energy } \\
\text { for sex }\end{array}$ & $6(13.3)$ & $37(82.2)$ & $2(4.4)$ \\
\hline To relieve stress & $10(22.2)$ & $33(73.3)$ & $2(4.4)$ \\
\hline $\begin{array}{l}\text { Other reasons, } \\
\text { such as }\end{array}$ & & & \\
\hline $\begin{array}{l}\text { Because of peer } \\
\text { pressure }\end{array}$ & $3(6.7)$ & $0(0.0)$ & $42(93.3)$ \\
\hline For pleasure & $18(40.0)$ & $0(0.0)$ & $27(60.0)$ \\
\hline
\end{tabular}

Table 2. Comparison between desires of participants to quit shisha with the history of attempt at quitting shisha

\begin{tabular}{|c|c|c|c|c|}
\hline \multirow[t]{2}{*}{ Questions* } & \multirow[b]{2}{*}{ Response } & \multicolumn{2}{|c|}{$\begin{array}{l}\text { Do you want } \\
\text { to stop/quit } \\
\text { smoking shisha? }\end{array}$} & \multirow[t]{2}{*}{ p-value } \\
\hline & & yes & no & \\
\hline \multirow{2}{*}{$\begin{array}{l}\text { During the past } \\
\text { year, have you } \\
\text { ever tried to stop } \\
\text { shisha smoking? }\end{array}$} & yes & 18 & 3 & \multirow[t]{2}{*}{0.026} \\
\hline & no & 12 & 10 & \\
\hline
\end{tabular}

*Only those participants who responded to cross-tabulated questions were computed in this statistics.

Joveini et al 2016, Momenabadi et al 2016, Davaji et al 2017, West 2017, Mugyenyi et al, 2018). This may suggest that most shisha smokers developed shisha smoking habit as a result of influence from close persons who were shisha smokers.

The reasons why our study participants smoke shisha were diverse; however, the two most common reasons why they 
smoke shisha were 'for pleasure' and 'to feel amongst'. The phrase 'to feel amongst' is a popular colloquial, and it means 'to have a sense of belonging amongst one's peers'. It has been well documented that many shisha smokers smoke shisha because they want to have pleasure and because they want 'to feel amongst' (Maziak et al 2005, Joveini et al 2016, Momenabadi et al 2016, West 2017, Mugyenyi et al 2018). For example, Mugyenyi et al (2018) qualitatively explored reasons why shisha smokers in the United Kingdom engage in shisha smoking habits; their findings showed that shisha smokers smoke shisha majorly because of these two above-mentioned reasons.

Unlike in some other studies, the majority of our study participants desired to quit shisha smoking habit (Davaji et al 2017, Mugyenyi et al 2018). For instance, in some similar studies conducted amongst Iranian and UK populations, it was found that majority of shisha smokers were not willing to quit shisha smoking habit (Davaji et al 2017, Mugyenyi et al 2018); the reasons why many of the shisha smokers surveyed in those studies were unwilling to quit the habits were based on the influence from medical practitioners (as some of them do see some medical doctors smoke shisha) as well as wrong perception of shisha smoking to be a harmless behaviour.

Interestingly, many of the study participants who desired to quit shisha smoking habit gave a report that they made attempt to stop the habit. Unfortunately, they are still engaging in this practice as at the time the data for this study were collected. On the basis of the afore-mentioned data, it shows that the participants in this present study need serious help in effectively quitting shisha smoking habit.

Furthermore, from our data analysis, we found that having or not having a close friend/family member/relative who smokes shisha is not significantly associated with participants' desire in quitting shisha smoking habit. On the basis of this finding, it implies that the desire to quit shisha smoking habit is not related with having a family tie with a shisha smoker. However, this finding is not consistent with that reported amongst Iranian shisha smokers (Davaji et al 2017), as many of them were found to show negative attitude towards quitting the habit because of influence from close friends and family ties.

\section{Study Limitations}

This study has some limitations [1]. This study's sample size was small; we used a small sample size in this study because of the difficulty in recruiting current shisha smokers because of difficulty in accessing shisha smokers at home and at shisha smoking places coupled with the problem of limited funding [2]. We used snowballing technique in the sampling of the study participants; this makes it difficult for all eligible participants standing at equal chance of being selected to partake in the study (because the sampling technique is a nonprobability sampling method) [3]. We only interviewed current shisha smokers living in the Birnin Kebbi LGA, Kebbi State; hence, shisha smokers in other LGAs were not included in this study, making it difficult to make generalisations about shisha smokers in Kebbi State.

\section{CONCLUSION}

This study has shown that there exist diverse reasons why shisha smokers engage in shisha smoking habit. However, the most popular reason why they engage in such habit was on account of pleasure seeking. Also, many of the shisha smokers interviewed in this study were willing to quit shisha smoking habit but, unfortunately, are yet to quit the habit. Also, having a close friend or relation who smokes shisha has no significant association with willingness of a shisha smoker to quit shisha smoking habit; however, having close relationship with such persons could influence one to start shisha smoking behaviour. Lastly, there is a need for social support of shisha smokers in Birnin Kebbi LGA area towards quitting shisha smoking habit.

\section{ACKNOWLEDGEMENTS}

We appreciate all those who participated in the study.

\section{CONFLICT OF INTEREST}

Authors have no conflict of interest to declare.

\section{DECLARATION OF ETHICS}

This study was conducted under the compliance with the Helsinki Declaration of 1964. Approval to carry out the study was obtained from the Kebbi Medical Centre, Kebbi State, Nigeria.

\section{DECLARATION OF INFORMED CONSENT}

The study data were collected anonymously, and informed verbal consent was obtained from the subjects before collecting the data. Confidentiality of the data was maintained, and any unauthorised exposure to data was not possible. 


\section{REFERENCES}

Afifi R, Khalil J, Fouad F, Hammal F, Jarallah Y, Abu Farhat H, et al. Social norms and attitudes linked to waterpipe use in the Eastern Mediterranean Region. Soc Sci Med 2013;98:125-34.

Al-Naggar RA, Saghir FS. Water pipe (shisha) smoking and associated factors among Malaysian university students. Asian Pac J Cancer Prev 2011;12(11):3041-7.

Al-Rawi NH, Alnuaimi AS, Uthman AT. Shisha smoking habit among dental school students in the United Arab Emirates: enabling factors and barriers. Int J Dent 2018;2018:2805103.

Bahelah R. Waterpipe tobacco labeling and packaging and World Health Organization Framework Convention on Tobacco Control (WHO FCTC): a call for action. Addiction 2014;109:333.

British Heart Foundation. Shisha. Accessed on January 06, 2019. URL: https://www.bhf.org.uk/heart-health/risk-factors/smoking/ shisha

Carroll MV, Chang J, Sidani JE, Barnett TE, Soule E, Balbach $E$, et al. Reigning tobacco ritual: waterpipe tobacco smoking establishment culture in the United States. Nicotine Tob Res 2014;16:1549-58.

City Population. Birnin Kebbi. Accessed on January 05, 2019. Available from URL: https://www.citypopulation.de/php/nigeriaadmin.php?adm2id=NGA022006

Control and prevention of waterpipe tobacco products (document FCTC/COP/6/11). Conference of the Parties to the WHO Framework Convention on Tobacco Control, Sixth session, Moscow, Russian Federation, 13 - 18 October 2014. Geneva: World Health Organization; 2014.

Davaji RBO, Shahamat YD, Davaji FH, Mirkarimi K, Charkazi A, Pahlavanzadeh B. Patterns, beliefs, norms and perceived harms of hookah smoking in North Iran. Asian Pac J Cancer Prev2017;18(3):823-30.

Encyclopaedia Britannica. Birnin Kebbi: Nigeria. Accessed on January 30, 2019. URL: https://www.britannica.com/place/BirninKebbi

Global adult tobacco survey: Nigeria country report 2012. Brazzaville: World Health Organization Regional Office for Africa; 2012.
Joveini H, Dehdari T, Ardebili HE, Mahmoudi M, Firouzian AA, Rohban A. Factors associated with hookah smoking among university students. Electron Physician 2016;8(12):3403-8.

Kanmodi KK, Fagbule OF, Aladelusi TO. Prevalence of shisha (waterpipe) smoking and awareness of head and neck cancer among Nigerian secondary school students: A preliminary survey. Int Public Health J 2018; 10(2):209-14.

Maziak W, Eissenberg T, Ward KD. Patterns of waterpipe use and dependence: implications for intervention development. Pharmacol Biochem Behav 2005;80:173-9.

Martinasek MP, McDermott RJ, Martini L. Waterpipe (hookah) tobacco smoking among youth. Curr Probl Pediatr Adolesc Health Care 2011;41:34-57

Momenabadi V, Kaveh MH, Hashemi SY, Borhaninejad VR. Factors affecting hookah smoking trend in the society: a review article. Addict Health 2016;8(2):123-35.

Mugyenyi AE, Haberer JE, O'Neil I. Pleasure and practice: a qualitative study of the individual and social underpinnings of shisha use in cafes among youth in the UK. BMJ Open 2018;8(4):e018989.

West R. Tobacco smoking: health impact, prevalence, correlates, and interventions. Psychol Health 2017;32(8):1018-36.

WHO Study Group on Tobacco Product Regulation (TobReg). Advisory note: Waterpipe tobacco smoking: health effects, research needs and recommendation actions by regulators, 2nd ed. Geneva: World Health Organization; 2015. 